\title{
PSYCHOTROPICS AND DELIRIUM: WHAT TO GIVE AND WHAT TO TAKE?
}

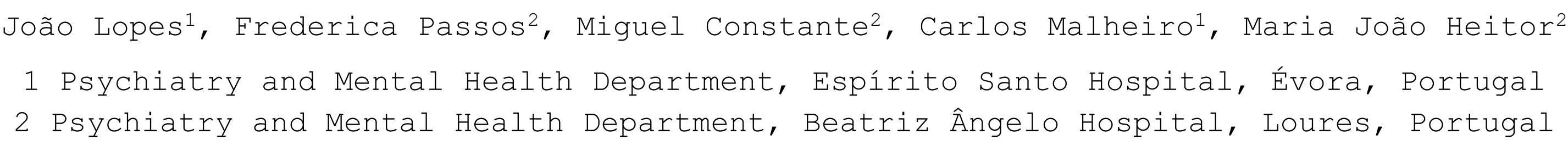

\section{Objectives}

To assess psychopharmacological management of delirium.

\section{Material and Methods}

Clinical case presentation and nonsystematic literature review on this topic.

\section{Background and Aims}

Delirium is a common, life-threatening, multiethiological syndrome that remains underrecognized and therefore mistreated, representing one of the most frequent referral reasons for liaison psychiatry in the general hospital.

Psychopharmacological treatment of this disorder has been subject of debate, therefore to assess this type of intervention and its correct use is of utmost importance.

\section{Results}

\section{- 89-year-old man}

- Previously diagnosed with early stage dementia but living independently, with no other relevant

\section{Case Report} medical history, prior to admission.

- Medicated with olanzapine $10 \mathrm{mg}$, galantamine $6 \mathrm{mg}$ and nebivolol $10 \mathrm{mg}$.

- Admitted with Community Acquired Pneumonia, which was complicated with multiorgan failure, culminating in septic shock and admission to ICU.

- $10^{\text {th }}$ day of admission: referred to Liaison Psychiatry, due to psychomotor agitation

The resolution of Delirium arises with the identification and treatment of the cause, being this the focal point of delirium management.

Several studies suggest that there is no benefit for the use of antipsychotic Vs placebo in the PREVENTION of delirium. To date, evidence supporting the use of antipsychotics in delirium remains elusive, other than when needed to control the symptoms of agitation.

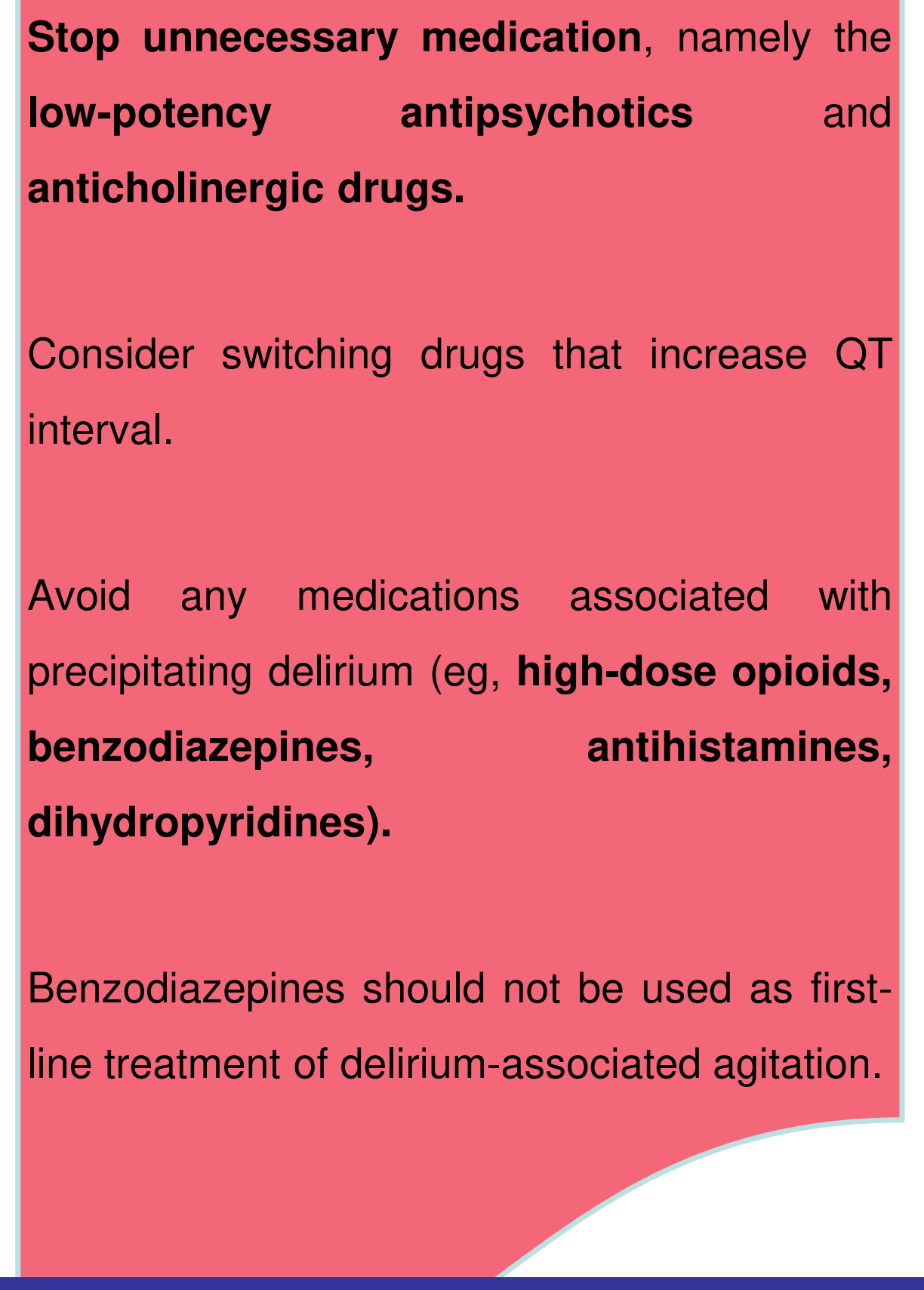

Haloperidol should be considered for first-line treatment for agitation: IV, if cardiac monitoring is possible, or IM/PO;

If QT interval is increased, consider atypical antipsychotics (olanzapine, risperidone or quetiapine).

Start slow, go slow.

\section{Conclusions}

This case and review highlights the importance of delirium in the general hospital setting, its prevention, management and the specific role of psychotropic medication within this syndrome's symptom monitoring and control.

\section{References}

Vardi K, Harrington CJ. Delirium: treatment and prevention. RI Med J (2013). 2014;97(6):24-8 Siddiqi N, Stockdale R, Britton AM, Holmes J. Interventions for preventing delirium in hospitalised non-ICU patients (Review). Cochrane Rev. 2016;(3):1469-93

Evensen S, Saltvedt I, Lydersen S, Wyller TB, Taraldsen K, Sletvold O. Environmental factors and risk of delirium in geriatric patients: an observational study. BMC Geriatr. 2018;18(1):1-8 Markowitz JD, Narasimhan M. Delirium and antipsychotics: a systematic review of epidemiology and somatic treatment options. Psychiatr (Edgmont). 2008;5(10):29-36 Thom RP, Mock CK, Teslyar F

Contact: joaogsmlopes@gmail.com

\section{Disclosure}

Cont: joagsmlopes@egmail.com 